\title{
Research of the Algorithm for the Work on Scientific Texts
}

\author{
Ainakul Bektasovna Tumanova ${ }^{1}$, Valentine Sergeevich Lee ${ }^{1}$, Zhamilya Serikovna Abaeva ${ }^{2}$, Elena Bronislavovna \\ Chekina $^{3}$, Raushan Smatbekovna Turebekova ${ }^{3} \&$ Gulbanu Kashkynbaykyzy Tleubay ${ }^{3}$ \\ ${ }^{1}$ Professor of the Department of Russian Philology, World and Russian literature, Kazakh National University \\ n.a. Al-Farabi University, Almaty, Kazakhstan \\ ${ }^{2}$ Associate professor of the Department of Russian Philology, World and Russian literature, Kazakh National \\ University n.a. Al-Farabi University, Almaty, Kazakhstan \\ ${ }^{3}$ Senior lecturer of the Department of Russian Philology, World and Russian literature, Kazakh National \\ University n.a. Al-Farabi University, Almaty, Kazakhstan \\ Correspondence: Tumanova Ainakul Bektasovna, Professor of the Department of Russian Philology, World and \\ Russian literature, Kazakh National University n.a. Al-Farabi University, Al-Farabi Avenue 71, 050040, Almaty, \\ Kazakhstan. E-mail: russian-science@mail.ru
}

Received: December 15, $2014 \quad$ Accepted: December 20, $2014 \quad$ Online Published: March 30, 2014

doi:10.5539/mas.v9n4p354

URL: http://dx.doi.org/10.5539/mas.v9n4p354

\begin{abstract}
The article focuses on teaching professional communication to non-philology students. The purpose of the article is to demonstrate an example of a particular text consistency and coherence stages at working with texts on their profession. A system of consistent actions is offered when working on scientific text (nine-step algorithm). This algorithm allows the student to not only learn how to understand and analyse scientific text on their profession, but also prepare them for self-production of the text. Eventually, it will prepare the student to creation of qualified scientific works on the topic of the research.
\end{abstract}

Keywords: text on the profession, algorithm for work, keywords, text compression, profession-oriented language

\section{Introduction}

Currently, the education system of the Republic of Kazakhstan identified the priority areas goaled at modernizing the existing system of education. Since 2005, the higher educational institutions of Kazakhstan introduced the educational method based on credits, the new state standards are being developed, the new subjects and elective courses are being introduced. The introduction of the course "The Professional Russian language" instead of "Practical course of the Russian language", in our opinion, can significantly improve the quality of education. For students of higher educational institutions, learning a professionally oriented language is not only a means of mastering the future profession, but also an opportunity to make future competent professional communication giving the chance for easy adaptation to the rapidly changing conditions of employment.

The idea of professional guidance is not new, but in accordance with the requirement of the time, it involves a completely new stage in its development. The necessity to move to a professional-oriented system of teaching the Russian language as a second language is forced by a number of objective, interrelated reasons. The first reason is global structural changes in the society. The second reason is the change of scientific paradigm in the science concerning language and related disciplines. The third reason is changes in language policy in Kazakhstan, and, as a consequence, changes in the social functions of the Russian language. The fourth reason is the change in the educational situation, introduction of new technologies and training standards in the educational space.

Information resources of society are now the determining factor of its development, both in scientific, technical, and social direction. In this sense, it is possible to state the allegiance of a well-known expression "who owns the information, owns the world".

Information exchange is the basis of all knowledge. Knowledge and information are, in fact, inseparable, but the two cannot be equated. Knowledge turns into information only when it is associated with communication 
capabilities. It is clear how important in today's world of information boom it is to teach future professionals, today's students, to carry qualified work with the primary source of information - text, which is essentially the language of the profession.

\section{Literature Review}

The scientific activity is deeply integrated into other areas of modern society. This activity is based on basic scientific communication, intellectual communication, optimizing the human mind, which development is stimulated by qualitative changes in the information arising from the knowledge (Volodina, 2000).

"The new information society" makes new demands on the organization of education in general and language learning in particular. The question is no in gaining knowledge in finished form, but on how to find them, process them, preserve, and use. The teacher's role in the modern higher educational institution, using the metaphor can be compared with the navigator, determining the direction of the search. Moreover, this is due primarily to the "avalanche" of information even on a single profession.

Linguodidactics, of course, has always depended on the state of the science of language, from the "object of science". Yu. N. Karaulov wrote "linguistics always returns to a discussion about the subject of their science" (Karaulov, 1989:11) and called the principal reason for this: the expansion of our experience, knowledge and understanding of language, and hence - the desire of linguists to rethink the problem and object of the study.

The history of scientific linguistics, according Yu. N. Karaulov, can be divided into several stages, characterized by the fundamental property of language, which comes to the fore, we present the determining factor in this or that period: "...one can identify the four paradigms - "historical", "psychological", "system-structural", and "social", each in its extreme expression denied the previous one, but which together synthesized to date scientific and linguistic paradigm (Karaulov, 1989)

Currently, linguistics has a firmly established new scientific anthropocentric paradigm: all the phenomena of language are considered. The principles, definitions, concepts, theories are formulated from the perspective of homo loquens (speaking human being). "Linguistic personality is the cross-cutting idea that, as the experience of its analysis and description, permeates all aspects of language learning and at the same time destroys the boundaries between disciplines studying a human being outside the language" (Karaulov, 1989).

Language teaching as a mirror reflects a paradigm shift in linguistic science in terms of goal setting: teaching speech, language, speech activity, and ways to communicate. Now the last goal - teaching communication - can be regarded as the major, and the rest - as intermediates compromising the value of each of them in no way. Currently, backbone and fundamental concepts for teaching languages is the concept of "linguistic identity" and "secondary language personality".

It can be said that the statement of goal - teaching how to communicate - causes no objections, but nevertheless, it requires some refinement in the framework of teaching a second language in higher educational institution, in accordance with the goals of higher education and student personal motivation - teaching a highly qualified specialist in this particular area and teaching the ability to solve professional problems, respectively. Naturally, the communication in higher educational institutions is shifting primarily into educational and professional sphere. Therefore, the goal of teaching a second language is specified: not teaching how to communicate in general, but teaching professional (intellectual) communication, which basis is a scientific text.

V. M. Zvegintsev very accurately determines the difference in the approaches to the understanding of the object in the study of communication activities. He writes that we can have two different objects, depending on our understanding the communication activities. If it is viewed only as a set of linguistic resources making it possible to communicate (including a set of units and the rules of their operating), we will have one object of study, which is the subject of the science of language for a long time and in many cases it remains till now. However, if both sides of activities connect a human being, then we will get a different object of study, where the meaning and process of its formation are on the first place (Zvegintsev, 1973).

It is the second approach in line with the anthropocentric paradigm, which seems to be optimal for the goal in the title - teaching professional (intellectual) communication. Formation processes of the meanings of a scientific text, their classification, methods of language fixation, handling meanings in different linguistic form and with different communicative settings outline the main content, in our opinion, for the Russian language courses for non-philology students.

With the formation of a sovereign state, the Language Act established a framework for functioning of languages in the Republic of Kazakhstan. The Russian language was assigned the status of official use "in state bodies and local self-government bodies on a par with the Kazakh language". B. B. Khasanov determined the status of the 
Russian language as the macrointermediary language and noted its dominant role in the education and state management (Khasanov, 2001). Change the official status of the Russian language leads to narrowing the scope of its use, and thus to a narrowing of its social function. E. D. Suleimenova (Suleimenova, 1996) states the preservation of the Russian language status in the field of intellectual communication (education, state management, technical activities). Probably, in the near future one may forecast the demand of the Russian language in the field of scientific communication.

The introduction of credit educational methods in Kazakhstan, ultimately goals to integrate into the world educational space, unifies the approaches to teaching and certification of the acquired knowledge. Their main ideology is a fundamental change in the role of the teacher and the student in the educational process. The main protagonist of the educational process is a student whose independent work takes up to $70 \%$ of the time allocated for education. In this respect, the role of "information channels" becomes crucial. "Educational and methodical strategy of "The Russian language" course shall ensure access of students in the Kazakh departments to the Russian scientific space that will allow them not only getting a professionally-oriented scientific information, but also the opportunity for declaring themselves as a subject capable of professional international communication through the Russian language"(Ekshembeeva, 2003).

The concept of goal setting in teaching the Russian language in a non-linguistic higher education institution can be formulated as follows: secondary language personality in the process of intellectual communication in the Russian-language cognitive-informational space.

The necessity to transfer to a professional-oriented system of teaching the Russian language as a second language (the Russian language is the language of international communication) is forced by a number of objective, interrelated reasons. The first reason is global structural changes in the society. The second reason is the change of scientific paradigm in the science concerning language and related disciplines. The third reason is the change in the social function of the Russian language in Kazakhstan. The fourth reason is the change in the educational situation, introduction of new technologies and training standards in the educational space.

As it is known, the basis of teaching professional communication is a scientific text. In our research, we rely on the work of domestic and foreign scientists, such as I. R. Halperin (Halperin, 1981), A. A. Zalevskaya (Zalevskaya, 2000), V. E. Chernjavskaja (Chernjavskaja, 2007), S. A. Vishnjakova (Vishnjakova, 2001), M.Sh. Musataeva, J. G. Amirova, L. V. Ekshembeeva (Musataeva, Amirova, Ekshembeeva 2012).

A text is a multi-level and complex formation. In this regard, science has no common understanding and interpretation of this concept. However, in all the concepts necessarily note, firstly, the principle of connectedness based on semantic interdependence of its parts/components of different levels; secondly, any text is the highest communicative unit. Summarizing all the points of view on the understanding of the text as a linguistic unity of a higher order, J. G. Amirova says, "On the one hand, a text as a semantic-syntactic unity, is a hierarchy of semantic units, and on the other hand, it is the integration of isomorphic units based on certain syntactic models. Therefore, the segmentation of the text may be directed to segmentation of semantic or structural-semantic units in it. Accordingly, scientists allocate semantic and structural-semantic segmentation of the text, reflecting different levels of the text organization as a dimensional model" (Amirova, 2002). This understanding of the text is taken as a basis in the practice - in the work on scientific texts on the profession.

\section{Materials and Methods}

\subsection{The Main Stages of Work on Scientific Texts}

The purpose of this article is to show the sequence and interconnectedness of stages of work on the scientific texts on their profession. Each stage (step) of work with the text has independent significance, and may become the subject of a separate discussion. In addition, giving equal attention to each stage in one article is not possible. Therefore, a closer look shall be paid to those moments, which, in our opinion, cause the greatest difficulty, for both the teachers and the students.

Schematically, the nine-step algorithm for work with text on the profession is as follows:

\begin{tabular}{|c|c|c|c|c|}
\hline 1th step $\rightarrow$ & & $\rightarrow \quad$ 2nd step $\rightarrow$ & & $\rightarrow \quad$ 3rd step $\rightarrow$ \\
\hline
\end{tabular}




\begin{tabular}{|c|c|c|}
\hline $\begin{array}{l}\text { Segmentation of the text into } \\
\text { semantic parts, based on the key } \\
\text { words of each part. }\end{array}$ & $\begin{array}{l}\text { Formulation of the topic of each } \\
\text { semantic part (denominative plan). }\end{array}$ & $\begin{array}{l}\text { Definition of the } \\
\text { communicative task of } \\
\text { semantic parts and its } \\
\text { detalisation (detailed plan). }\end{array}$ \\
\hline$\rightarrow 4$ & $\rightarrow$ 5th & $\rightarrow$ 6th step $\rightarrow$ \\
\hline $\begin{array}{l}\text { Formulation of the question to } \\
\text { the general word of each semantic } \\
\text { part (question plan). }\end{array}$ & $\begin{array}{l}\text { Formulation of the question to } \\
\text { the general word of each semantic } \\
\text { part (thesis plan). }\end{array}$ & $\begin{array}{l}\text { Scientific presentation of the } \\
\text { text content based on the } \\
\text { denominative plan (short } \\
\text { version). }\end{array}$ \\
\hline$\rightarrow 7 t$ & $\rightarrow$ 8th s & $\rightarrow$ 9th step \\
\hline $\begin{array}{l}\text { Scientific presentation of the text } \\
\text { content based on the denominative } \\
\text { plan (detailed version). }\end{array}$ & $\begin{array}{lrr}\text { Making } & \text { secondary } & \text { text } \text { using } \\
\text { special linguistic } \text { resources } \\
\text { (abstract, synopsis, summary). }\end{array}$ & $\begin{array}{l}\text { Making secondary text using } \\
\text { special linguistic resources, } \\
\text { expressing the assessment } \\
\text { (comment, review). }\end{array}$ \\
\hline
\end{tabular}

Work with text was carried using the example of biological text "Pigments" consisting of 4 paragraphs.

1) Chromogenic bacteria colonies (clusters of bacteria cells) on solid media get coloured in red (Scrratia marscents, actinomycetes, yeast), pink (Pink micrococcus), gold (Staphylococcus aureus), white (white staphylococcus), purple (purple chromobacterium), black and brown (yeast and fungi), yellow or orange (Mycobacterium tuberculosis) and other colours. Some microorganisms produce two or more pigments. Thus, the Saracens colonies are painted in yellow, lemon, and golden colours.

2) Chromogenesis occurs at good availability of oxygen, temperature around 20-25 degrees and, for the most species, in diffuse sunlight.

3) Pigments are classified into water-soluble (e.g., blue-green milk bacteria), alcohol-soluble and insoluble in water and alcohol (Azotobacter, black and brown pigments of yeast and molds), as well as chromopaired (coming into the external environment), and the chromophore (found in the cytoplasm, vacuoles, and shell).

4) Chromogenesis in bacteria has a definite physiological significance. Perhaps pigments perform the hydrogen acceptor function during respiration processes. They provide protection from the natural ultraviolet radiation. Additionally, pigments are involved in synthesis reactions. Moreover, they possess antibiotic action.

Step one - Segmentation of the text into semantic parts, based on the key words of each part:

1) Keywords of the first paragraph - "microorganism" (and its synonyms "microbes", "bacteria") and "get painted" (and its contextual synonym "produce pigments".

2) Keyword of the second paragraph is "chromogenesis".

3) Keywords of the third paragraph - "pigments", "classified."

4) Keywords of the fourth paragraph are "chromogenesis", "meaning".

Then it is possible to assume that the boundaries of semantic units and paragraphs in this text coincide. However, this assumption still demands its acknowledgment at determining the topics and communicative tasks of the semantic part.

Step two - Formulation of the topic for each semantic part. Topic is a subject or phenomenon discussed in the text. Often the word for the topic in the text is repeated. It is called the word-topic. Usually, a noun represents the topic in the text. This noun can occur in different cases. The word-topic may be replaced by a pronoun or a synonymous expression. Most often, the topic is indicated in the first, second or third sentence, the guides at defining the topic - the subject of conversation - shall be the first word and the repeated word. Let us define sequentially the subject of speech in each semantic part:

1) Chromogenic bacteria (the subject of speech is chromogenic bacteria).

2) Colour producing (this entails colour producing). 
3) Pigments (this entails pigment).

4) Chromogenesis (this entails chromogenesis). Denominative plan results from this activity.

Step three - Identification of the communication task (CT) for the semantic part. As part of the structural and semantic segmentation, orienting basis for all further actions with the text on the profession is formed. Basic concepts of structural and semantic segmentation of the text are the topic of the text (T), communicative task of the text (CT) microtopic of the text (MT), datum (D) and the new (N) information of the text, the text progression, the way of the text information development, and the structural semantic model of the text. These concepts are necessary to understand the logic of the finished structure of a scientific text and producing own texts.

\subsection{Semantic (Communicative) Segmentation of the Scientific Text as a Special Kind of Academic Work}

Talking about the structural and semantic segmentation of the text in terms of goal-setting, the following goals and objectives can be formulated: to help students in the perception and production of text on their profession, to teach how to understand the patterns of the text; to see the close relationship of meaning and form of the text and heading information text; to build a model of the text and then to reproduce it based on the content of the text with different goals.

The topic and communicative task of the text constitute a dialectical unity and cannot exist without each other. Topic is a subject or phenomenon discussed in the text. Often the word, meaning the topic in the text, is repeated. It is called the word-topic. Usually, a noun represents the topic in the text. This noun can occur in different cases. The word-topic may be replaced by a pronoun or a synonymous expression.

Any text, as already mentioned, has a certain topic. However, any topic can be viewed from different sides depending on the communication task put by the author. For example, the text about property may have different form. It may contain only a general idea of the property. This text may contain the information about forms of ownership, the difference of ownership forms may be explained in different periods of the society development, and this concept may be considered in the legal aspect. Thus, different texts may be written on the same topic. This explains how the text develops depending on the communicative task. The communicative task of the text is the task put by the author in front of him and the reader and for the disclosure of which the text is created. The communicative task may be referred explicitly by the author, i.e. it can be expressed in one of the sentences of the text, often in the beginning. In this case, there are no difficulties in determining CT. This is the first method for determining the communicative task of the text. For example: In the process of reforming the economics, Kazakhstan used the experience of different countries. Prior to 1998, Kazakhstan followed the Anglo-Saxon option. Anglo-Saxon liberal society characterizes with individualism, limited role of the state, and the focus on macroeconomics. However, since 1998 the country stopped adhering to any particular model of a mixed economics, using for its development a positive experience and best achievements of all civilizations with proven effectiveness. The topic of the text provided above is reforming the economics of Kazakhstan. Communicative task of the text is using the experience of different countries. It is reflected in the first sentence. The first method for determining CT (1) is the key sentence. The way for formulating the communicative task is the formulation of the verb used to express predicate and substantive: Kazakhstan used the experience of different countries - using the experience of different countries.

The second method for determining the communicative task of the text is used when the communicative task is not reflected in the specific sentence, but is implied. In this case, it is necessary to define the description subject, to identify the particular characteristics (by the structure, composition and the role, meaning, properties, etc.), and only then it is possible to make a conclusion on the communicative task. For example: The central bank is often the property of the state. Through its work at the macro level, it reflects the national interest, and carries the policy not in the interests of a particular region or a group of national economy sectors, but in the interests of the state as a whole. Being the banker to the government, the central bank acts as its cashier and creditor, it opens accounts for the government and government agencies. The central bank usually provides cash administration of the state budget. At that, the central bank does not goal to make profit. The topic of the provided text is the central bank. The text contains no sentence to generalise and to synthesise the information. Each sentence reveals some feature about the central bank. Consequently, the communicative task (CT) of the text refers to the role (meaning) of the central bank in the country. The method for determining the communicative task (2) - analysis of the text semantic content, its generalization, i.e. categorization (reduction of all the semantic content to a word or a word combination).

The most frequent communication tasks of a scientific text is giving a definition or an idea of the subject and the phenomenon; demonstrating the structure, frame or composition of the researched subject, as well as its shape 
and properties; determining the function, the role, the purpose of the subject and the phenomenon; determining the impact, influence, relationship of the object and the phenomena; including this or that object to the type, grade, rank, group, etc., that is to classify the objects and the phenomena.

Microtopics are the part of an overall topic, consisting of one or more sentences united in meaning and revealing from different the communicative task of the text from different sides. Metaphorically, microtopics may be called the "points of growth" of the text. The text can contain two or more microtopics. Each microtopic (MT) may consist of one or more sentences. For example: The human body consists of a head, a trunk, and limbs. The head contains cranial vaults and the facial area. The trunk includes the chest, the abdomen, and the back. Limbs are divided into upper and lower. The topic of the text is the human body. Its communicative task is the human body structure. It is indicated in the first sentence. Since the question is the structure, the microtopics (MT) denote the structure of the object's parts: MT-1 - head (2 objects), MT-2 - trunk (3 objects), MT-3 - limb (4 objects).

Semantic segmentation of the text represents the evolution of a thought. It is carried out from any source known information to the unknown information. The elements of thought development and text coherence include the datum and the new information. The text information datum (datum - D) - is the source information from which the thought development starts. It is contained in a sentence transferring the communicative task (CT) of the text. Text datum is transferred by a word or a word combination reflecting the communicative task best. The role of the datum is to contribute to the text development. For example: There are two ways of applying the current to the tissue for measuring the stimulation threshold and thus determining their excitability. The first method extracellular - implies that both electrodes are arranged on the stimulated tissue surface. Conventionally, it is assumed that the applied current enters the tissue in the anode area and exits it in the cathode area. The second method for delivering current to cells - intracellular - implies that the microelectrode is introduced into the cell, and the normal electrode is arranged to the tissue surface. Communicative task of the text is stated in the first sentence - Two ways to deliver the current to the tissues. The word combination two ways shall express the communicative task in the most accurate way. The text is created to find out exactly the existing methods and the way they differ. Therefore, in this text, the word combination two ways for delivering current to the tissues is the given text information - the datum (D). This information is disclosed in the subsequent sentences. They describe the first and then the second methods sequentially.

The new of the text (new - N) means unknown information in the text, which is to be learned (to get across). This information usually has generalized meaning (broadly characterized). New information of the text reveals and specifies this information, influences the development of the text semantic. For example: Conventionally, there are three types of lymph nodes in ratio of cortical and medullary substance. The first type is characterized in having cortical substance area smaller than medullary substance area. Lymph nodes of the second type are compact. They are characterized by cortical substance predominating over medullary substance. Lymph nodes of the third type - intermediate - are the most common having the same weight of cortical and medullary substances. The topic of the text is the lymph nodes. Communicative task is reflected in the first sentence: Conventionally, there are three types of lymph nodes. The word combination three types of lymph nodes reflect CT in the most exact way. Therefore, it is a source of information, the datum (D) of this text, which will be disclosed later. The datum is disclosed in microtopics using the new information - the new (N). For MT-1 (the first type), the new information is the area of the cortical substance less than the area of medullary substance - N-1. For MT-2 (the second type), the new information - compact - N-1, and the predominance of the cortical substance over medullary substance - N-2; for MT-3 (the third type), the new information - intermediate - N-1 and the same weight of the cortical and medullary substances $-\mathrm{N}-2$. The amount of the new information in one microtopic may vary depending on the text content.

\section{Results and Discussion}

The main text connections can be represented by the following model. The model of the text is a reproduction of the main text connections getting across the thought development: topics, communicative tasks, datum, and the new information. The model of the text can be got across verbally and can be fixed in the form of diagrams, i.e. graphic model (see the model-diagram): 


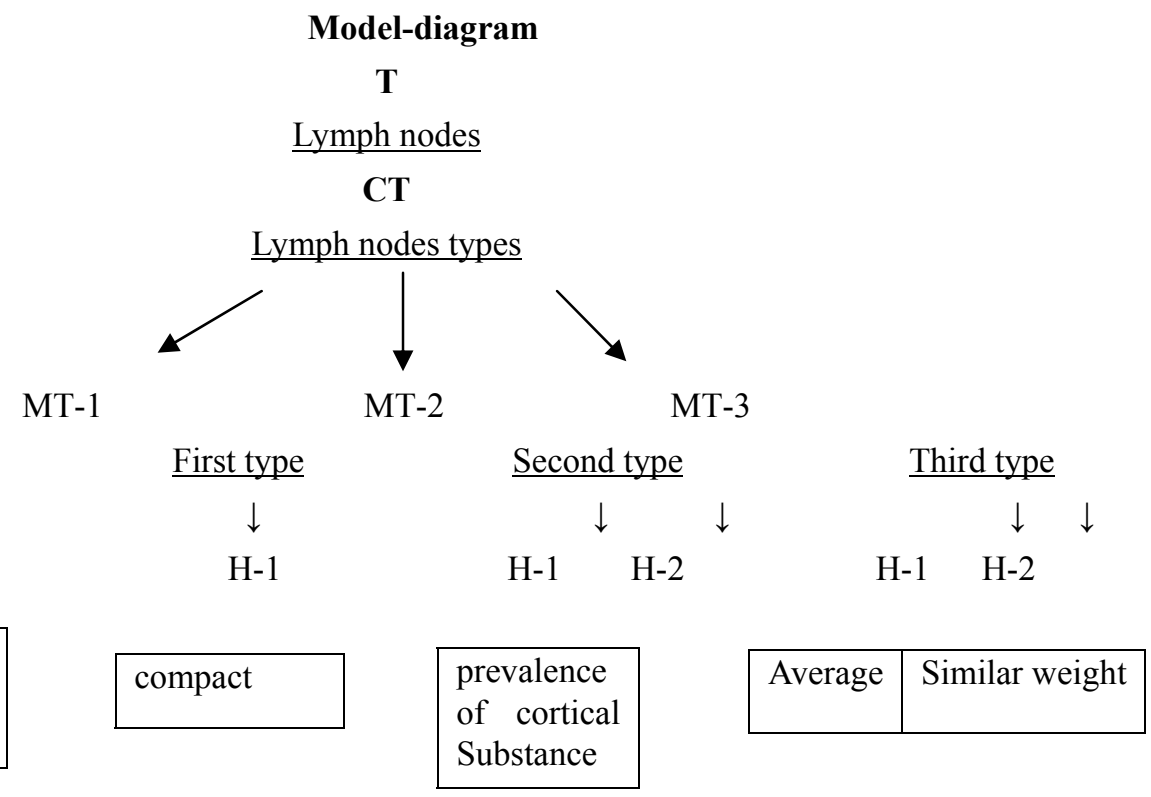

As already mentioned, the structural and semantic segmentation gives an indicative basis for all further manipulations with the text, while the basis is detailed and developed step-by-step, which encourages students to approach consciously to speech activity, relying on the most typical adult sides of mental activity - logic thinking and logic memory .

CT is defined in different ways depending on the content. When communicative task is formulated by the author of the text and is located in the first (but not always) sentence of the semantic part, as it happens, for example, in the fourth paragraph of the text analysed above: "Chromogenesis in bacteria has a definite physiological significance". In the subsequent sentences, CT is disclosed: pigments are involved in the respiration process; provide protection; are involved in the synthesis; are antibiotics. Therefore, CT of this piece of text is "physiological significance of chromogenesis". In another case, when there is no direct expression of CT, it is necessary to analyse the semantic content of the semantic part - what is exactly said about the subject of the speech and carry out the categorization procedure, i.e. find the general word for this content. The second and third parts of the text pose no difficulties for semantic content generalization. The second part lists the conditions under which chromogenesis occur: availability of oxygen, a certain temperature, and diffuse sunlight. Hence, CT of this fragment is "Conditions for chromogenesis", which are to be formulated as a denominative sentence.

Semantic content of the third semantic part is as follows: "The pigments are divided into different groups". If the set of objects is divided into groups, classes, types, species, etc., then we are dealing with the classification of objects or phenomena on various bases. We can conclude from the above said that the CT of this fragment is as follows: "Classification of pigments in solubility", which types are to be summarized as well using denominative sentences. This work results in a detailed plan.

Let us make an analysis of the first semantic part of the text from this point of view. Generalized subject content can be expressed as follows: chromogenic bacteria colonies on solid media get painted in different colours: red, yellow, etc. It means that the first, the simplest, and the most elementary categorization is COLOUR. However, let us turn to the text - ...on solid media get painted... Therefore, colour is either non-original quality of bacteria, or the result of changes in the conditions of bacteria existence or certain manipulations. The next step would be the word "colouring". In addition, that would be enough within microtext without considering the space of the entire text. The result of categorization applied to the subsequent microtexts will include: "conditions", "classification", and "physiological significance." A logical conclusion is that the word "colouring" is dissonant with the rest of the categories: "conditions", "classification", and "significance". Semantic volume of the word "colouring" does not meet this level of categorization. The next step is taking the words "colour", "colouring" under the category of a higher generalization level - "properties". As a result, CT of this fragment can be formulated as follows: "The property of chromogenic bacteria".

\section{Conclusion}

Formulation of communicative tasks for each semantic part, in addition to understanding the meaning of the text, 
has a purely practical purpose - realization of text compression in the denominative, and then detailed plan. Let us fix the formulation for the communicative task of each semantic part in the form of the detailed plan:

1. Property of chromogenic bacteria.

2. Terms for chromogenesis:

a) Good oxygen supply;

b) The temperature of 20 - 25 degrees;

c) Diffuse sunlight.

3. Pigments classification by solubility:

a) Water soluble;

b) Alcohol soluble;

c) Insoluble in water and alcohol;

g) Chromo-paired (entering into the environment);

d) Chromophore (located in cytoplasm, vacuoles, and shell).

\section{Physiological significance of pigmentation.}

Step four - Formulation of the question to the general word of each semantic part. The role of the question in the interpretation of the semantic content of a piece of text can be twofold: it can be used in the information compilation function and information deployment function. When the semantic content is created by a few sentences, but can be minimized to a single sentence, then in this case the question will perform the generalization function best. Let us show this by the example of the last paragraph:

Chromogenesis in bacteria has a definite physiological significance. Perhaps pigments perform the hydrogen acceptor function during respiration processes. They provide protection from the natural ultraviolet radiation. Additionally, pigments are involved in synthesis reactions. Moreover, they possess antibiotic action.

1) What is the physiological significance of chromogenesis in bacteria?

2) The physiological significance of chromogenesis in bacteria consists in performing various functions such as hydrogen acceptor in the process of respiration, the natural UV-protection, antibiotic protection, participation in synthetic reactions.

The question performed the generalization operation without violating semantic integrity, but with changing the structural organisation (five sentences are combined into one).

Further, the question can also perform the opposite action - the deployment of the information contained in the semantic category, the process of which was described above. Let us take the category of "meaning" as an example. The conceptual system of any native speaker (who learned the basics of science in the high school) contains a stereotypical set of questions corresponding to a specific semantic category. The given semantic category - "meaning" - shall have the following question in the stereotypical set: 1 . What is the meaning of.... 2 . What meaning does ... have? 3. What does carry the meaning of...? 4 . What does contain the meaning of...?

A very common way of "catching" the meaning is paraphrasing $(9, p .170)$. Let us write out the questions to the general word of each semantic part. This results in a compressed version of the text in the form of a question plan:

1. Which property do chromogenic bacteria have?

2. What are the conditions for chromogenesis?

3. In what groups can the pigments be divided on solubility?

4. What is the physiological significance of chromogenesis?

Step five - The answer to the question to the general word of each semantic part. Let us answer the question using the information of sentences expressing the communicative task of the semantic part, or in accordance with the structural pattern (model) of the sentence, which is used to formulate the question, or in another form, but retaining the semantic content. As a result, we get the thesis plan of the text:

1. Chromogenic bacteria on solid media are painted in different colours (alternatively: chromogenic bacteria posses. The quality to get painted different colours on solid media).

2. Chromogenesis occurs at availability of oxygen, temperature of +25 degrees and diffuse sunlight (as an option: 
the conditions for chromogenesis are the access of oxygen, temperature not less than +25 degrees and diffuse sunlight).

3. Pigments are divided into soluble and insoluble in water and alcohol.

4. The physiological significance of chromogenesis in bacteria consists in performing various functions, such as: hydrogen acceptor in the process of respiration, natural UV protection, antibiotic protection, participation in synthesis reactions.

Step six - Scientific presentation of the text content based on the denominative plan (short version). Scientific statement of the text contents is a retelling of the source text content with the help of special linguistic resources, such as verbs, verbal and nominal phrases, while certain types of information correspond to certain verbs groups:

1. Objectively basic information of the source text is to be entered in the metatext using the following lexical units: report, speak, write, draw, point, stop, pay attention, give attention to, dedicate (the article) to the problem, as well as the impersonal verbal-nominal word combination the question is;

2. Information that the author of the source text considers as important, is introduced using the following verbs: to emphasize to focus, to point out, to stress;

3. Secondary information, which is not important from the point of view of the author of the source text, is introduced using a special verb to mention, as well of the verbs of the first group, but with the support of other lexical means: occasionally, casually.

Scientific statement of the source text can be made in either a compressed or an expanded form. Scientific statement of the content in short form is based on the communicative problem formulated as a denominative sentence. Detailed scientific statement of the source text content is based on the thesis plan.

Step eight - Making secondary text using special linguistic resources (abstract, synopsis, summary). The following option for the abstract description of the text "Pigments" in the form of a synopsis is offered:

In the first section of the text, the author writes that the chromogenic bacteria on solid media are painted in different colours. In the second part of the text, he stops on the fact that the chromogenesis occurs in the availability of oxygen, temperature of +25 degrees, and diffuse sunlight. Further attention is drawn to the fact that the pigments are divided into soluble and insoluble in water and alcohol. In conclusion, the author says that the physiological significance of chromogenesis in bacteria consists in performing various functions (hydrogen acceptor in the process of respiration, natural UV protection, antibiotic protection, participation in synthesis reactions).

Step nine - Making secondary text using special linguistic resources, expressing the assessment of the text content (comment, review). It is clear that in the final stage of the work on the scientific text, the reader/trainee is ready to express any particular attitude to the researched information and give personal assessment from the personal point of view. Next we provide a fragment of a comment/review to illustrate our words: The author describes in detail how chromogenic bacteria on solid media get painted in different colours. The text gives precise information about the chromogenesis conditions. Author visualises the classification of pigments. We agree with the authors' conclusion that the physiological significance of chromogenesis in bacteria consists in performing various functions by pigments.

The text contains informative data and may be of interest to students with a degree in "Biology".

The educational strategy considered in this paper - the nine-step algorithm for working on the text on the profession - is important in linguistic-didactic and methodological aspects. It shows the overall picture and the possibility of manipulations with text having different purposes. In addition, it gives the chance to see the interconnectedness and continuity of all the operations with it. Therefore, a properly planned scientific work on the text on the profession will help the student to the study the professionally oriented language, its assimilation and application in educational, professional, and future career activities.

\section{References}

Amirova, J. G. (2002). Segmentation of text and language universals. Proceedings of the international scientific practical conference. The World of Language, 10-14. Almaty: KazUIR\&WL.

Chernjavskaja, V. E. (2007). Scientific text interpretation: Course Book. M. 128.

Ekshembeeva, L. V. (2003). Educational space and ways for modeling. Actual problems of functioning and 
teaching of language and literature. Karaganda.

Galperin, I. R. (1981). Text as an object of linguistic research. M.: Nauka. 139.

Karaulov, Yu. N. (1989). Russian language and linguistic identity. M.

Khasanov, B. H. (2001). Russian language in Kazakhstan on a platform of linguistic sovereignty. The Russian language in the socio-cultural environment of the XXI century. Almaty.

Musataeva, M. Sh., Amirov, J. G., \& Ekshembeeva, L. V. (2012). Theoretical and methodological aspects of learning text linguistics and discourse. Almaty, 294.

Pahnova, T. M. (2002). Stages of work on the scientific text. M.: Drofa.

Suleimenova, E. D. (1996). The Kazakh and Russian languages: the contrastive linguistics basics. Almaty.

Tumanova, A. B. (2011). Text as an object of teaching the Russian language in a technical educational institution. Collection of proceedings of the III International Scientific Conference "The text in the system of teaching the Russian language and literature"/ Generally Edited by E. A. Zhuravleva, Sh. K. Zharkynbekova. May 23-24, 2011. Astana: ENU. p. 283-288.

Tumanova, A. B. (2014). The Russian language. Scientific style of speech. Textbook (2nd ed.). Ext. Almaty, 147.

Vishnjakova, S. A. (2001). Theoretical basics for teaching scientific text modelling. Saint-Petersburg, 258.

Volodina, M. N. (2012). Cognitive and informational nature of a term. Moscow State University, 2000.

Work on the scientific text: compression, transformation, representation. Collection of the VII International Conference "Russian speech culture and text." Tomsk, p. 378-383.

Zalberman, L. I. (2000). On the question of the semantic text analysis in the process of teaching reading. M.

Zalevskaja, A. A. (2000). Text and its understanding. Tver, 153.

Zvegintsev, V. A. (1973). The language and linguistic theory. M., 170.

\section{Copyrights}

Copyright for this article is retained by the author(s), with first publication rights granted to the journal.

This is an open-access article distributed under the terms and conditions of the Creative Commons Attribution license (http://creativecommons.org/licenses/by/3.0/). 